\title{
PRODUÇÃO TEXTUAL NO ENSINO DE LÍNGUA ESPANHOLA: UMA EXPERIÊNCIA COM LIVRO CARTONERO NO CEFET/RJ
}

\author{
TEXTUAL PRODUCTION IN SPANISH LANGUAGE TEACHING: \\ AN EXPERIENCE WITH CARTONERO BOOK AT CEFET/RJ
}

\author{
Fabiana Oliveira de Souza *
}

\begin{abstract}
Resumo: O objetivo deste artigo é relatar uma experiência de produção textual em língua espanhola que culminou na elaboração e publicação de um livro cartonero, cuja capa é feita de cartón, "papelão" em espanhol. A partir dos debates sobre meio ambiente e temáticas afins, tendo como subsídio diferentes gêneros discursivos analisados em cada aula, propôs-se que os estudantes produzissem um texto abordando um desses temas. Resultado das atividades desenvolvidas ao longo de um semestre na disciplina de Língua Espanhola com a turma do quarto ano do Ensino Médio do CEFET/RJ, campus Petrópolis, o livro auxilia na formação cidadã desses alunos e faz dialogar teoria e prática, por ser não apenas uma discussão sobre conscientização, mas também uma ação coletiva de reciclagem. A obra atende às expectativas de um curso de língua estrangeira preocupado com a transdisciplinaridade, enfatizando temáticas transversais e interagindo com o mundo para além da instituição de ensino.
\end{abstract}

Palavras-chave: Produção textual. Ensino de Espanhol. Livro cartonero. Ensino Médio. Rede federal de educação.

\begin{abstract}
The purpose of this paper is to report an experience of textual production in Spanish, which culminated in the elaboration and publication of a cartonero book, whose cover is made of cartón, "cardboard" in Spanish. Based on the debates on the environment and related themes, with the support of different discourse genres analyzed in each class, it was proposed that the students produce a text addressing one of these topics. Result of activities developed throughout a semester in Spanish Language with the last grade of high school class of CEFET/RJ, Petrópolis campus, the book helps in the citizen formation of these students and enables the dialogue between theory and practice, as it is not only a discussion about awareness, but also a collective recycling action. The work meets the expectations of a foreign language course concerned with transdisciplinarity, emphasizing transversal themes, and interacting with the world beyond the educational institution.
\end{abstract}

Keywords: Textual production. Teaching of Spanish. Cartonero book. High School. Federal education network.

\section{Introdução}

A produção textual é uma prática discursiva, a qual, por sua vez, é imprescindível para significar o nosso ser e estar no mundo, porque garante nossa interação com nossos pares. Uma vez que são fundamentais para garantir as relações entre os seres humanos, as atividades linguísticas devem acontecer e ser motivadas constantemente no âmbito escolar, a partir de um trabalho sensível, engajado e responsável, interessado na valorização do processo educativo e na formação completa do educando, uma formação para a vida.

A relevância do projeto que será detalhadamente descrito e relatado neste texto está em seu propósito de contribuir com a construção de uma educação de qualidade, conforme argumenta-se nos Parâmetros Curriculares Nacionais:

\footnotetext{
* Professora substituta do Instituto de Letras da Universidade do Estado do Rio de Janeiro (UERJ). Doutoranda em Letras Neolatinas pela Universidade Federal do Rio de Janeiro (UFRJ). Bolsista CNPq. E-mail: biyanajass@gmail.com
} 


\begin{abstract}
Nos produtos da atividade humana, sejam eles bens, serviços ou conhecimentos, a estética da sensibilidade valoriza a qualidade. Nas práticas e processos, a busca de aprimoramento permanente. Ambos, qualidade e aprimoramento, associam-se ao prazer de fazer bem feito e à insatisfação com o razoável, quando é possível realizar o bom, e com este, quando o ótimo é factível. Para essa concepção estética, o ensino de má qualidade é, em sua feiúra, uma agressão à sensibilidade e, por isso, será também antidemocrático e antiético (BRASIL, 2000a, p. 63).
\end{abstract}

O presente artigo apresenta um relato de experiência com um projeto de elaboração coletiva de um livro cartonero com uma turma de ensino médio, que procurou combater essa "feiúra" que os PCNs denunciam. O trabalho incluiu produção textual em língua espanhola nos gêneros conto, crônica e poesia, além da fabricação das capas que abrigariam os livros, utilizando-se um material reciclado: o papelão, cartón em espanhol, que deu origem ao nome cartonero. A partir dos debates sobre meio ambiente e temáticas relacionadas, suscitados em sala de aula com base nos diferentes textos de variados gêneros discursivos analisados em cada encontro - e que estão elencados, na seção 5 -, propôs-se a ideia de que cada estudante produzisse um texto em espanhol sobre uma dessas temáticas. Cabe salientar que esse processo de escrita compreendeu diferentes etapas, como o rascunho, a primeira escrita, a revisão (e retorno aos alunos), a reescrita e última revisão, caso fosse necessário.

Resultado das atividades desenvolvidas ao longo de um semestre na disciplina Língua Estrangeira IV - Espanhol com a turma do quarto ano do curso técnico em Telecomunicações integrado ao Ensino Médio do Centro Federal de Educação Tecnológica Celso Suckow da Fonseca (CEFET/RJ), no campus Petrópolis, o livro que reúne os escritos desses alunos representa uma forma de auxiliar sua formação cidadã ao fazer dialogar teoria e prática, uma vez que não apenas se discutiu a conscientização sobre questões ambientais prementes nos dias correntes, mas também proporcionou uma ação a este respeito ao construir-se um livro cuja capa é feita de material reutilizado. Ademais, a obra, fruto de um trabalho conjunto entre discentes, docentes e a editora Ganesha Cartonera, pela qual foi publicada, simboliza aquilo que se espera de um curso de língua estrangeira voltado para a prática transdisciplinar, interagindo com temas transversais e com o mundo para além da instituição de ensino.

Em primeiro lugar, destacarei as contribuições teóricas que são basilares para compreender a pertinência do projeto, tendo em vista o contexto em que se concretizou. Além disso, tais teorias nos orientam para uma adequação (a uma turma de educação básica) da idealização e posta em prática de uma atividade que envolve leituras, reflexões, escritas, interações, produção artística e reciclagem.

Em segundo lugar, antes de começar o relato propriamente dito, farei uma breve passagem pelas origens desse tipo artístico-literário de produção que é o livro cartonero. Em seguida, informarei quem foram os sujeitos envolvidos e comprometidos com a proposta.

Por fim, relatarei toda a experiência que tivemos com nossa obra cartonera, explicando minuciosamente o projeto e cada etapa do processo, desde as primeiras aulas com a turma até a publicação do livro.

\title{
1 Bases teórico-didáticas para a composição do projeto
}


A ideia de levar o universo das editoras cartoneras para a sala de aula surgiu desde que soube de sua existência, em 2015. Ao pesquisar sobre um escritor argentino e estudar outros autores do mesmo país, tive contato com alguns livros com capas bem coloridas, características daquela que foi a pioneira nesse tipo de trabalho editorial: a Eloísa Cartonera, a qual retomarei na próxima seção.

O projeto ganhou força alguns anos mais tarde, quando surgiu, em 2018 no Rio de Janeiro, a Ganesha Cartonera, que segue a mesma proposta da editora argentina. A inspiração final para que eu começasse os primeiros esboços, pensando em meios para materializar esse projeto e planejando sua composição e metodologia, foi a consulta ao volume 3 do livro didático Confluencia, de Pinheiro-Correa et al (2016), que integra (junto aos demais volumes da coleção) o Programa Nacional do Livro e do Material Didático de 2018 e que foi produzido para servir de apoio aos docentes que lecionam língua espanhola no ensino médio.

$\mathrm{Na}$ Unidad 2, cujo tema se intitula ecopolémicas, há uma série de exercícios de leitura, produção textual, compreensão auditiva e produção oral, sempre conectados ao entorno dos estudantes e à diversidade dos países hispanofalantes, sob uma perspectiva intercultural, utilizando como ferramentas de trabalho gêneros discursivos variados, de fontes igualmente diversas, promovendo um estudo de seus aspectos e de suas funções sociais.

Durante as aulas, propus quase todos os debates suscitados na unidade, a partir do tema mais amplo que a nomeia. Dessa forma, ampliávamos nossos conhecimentos sobre o assunto, o que ajudaria os estudantes no momento de escreverem seus textos. Além dessa etapa de discussões, a essência do nosso projeto foi uma versão, com pequenas adaptações, das atividades sugeridas em duas seções: "Para escribir una crónica", em que se pede ao aluno que escreva uma crônica sobre um dos tópicos abordados em sala; e "Para movilizar mi entorno", na qual os autores contam um pouco da história da editora Eloísa Cartonera e indicam como projeto final da unidade a montagem de livros cartoneros. A recomendação é que os alunos se dividam em pequenos grupos para reunirem seus respectivos textos - as crônicas da seção precedente -, sendo também os responsáveis pela elaboração das capas de seu livro. Além disso, há a indicação de realização de uma Feira do Livro, onde as obras seriam exibidas. A feira seria organizada por várias turmas do colégio e incluiria uma oficina cartonera, com o intuito de incentivar os colegas a reproduzirem a ideia.

Outros dados e os detalhes do nosso projeto, o foco deste artigo, serão informados posteriormente. Antes, comento as bases teórico-didáticas que melhor fundamentam as atividades que desenvolvemos, lembrando que se tratava de uma turma do último ano do Ensino Médio.

Existe uma vasta produção científica a respeito do conceito de língua e linguagem, do ensino de línguas estrangeiras e, mais especificamente, de espanhol. São trabalhos que resultaram de investigações preocupadas em compreender, acompanhar, descrever e promover práticas linguísticas cada vez mais apropriadas a um ensino que se quer alinhado ao seu tempo, incentivando uma atuação reflexiva do docente.

Além das especificidades linguísticas da língua espanhola, é preciso proporcionar um ensino atento às questões culturais, políticas, econômicas e históricas que a caracterizam. Estudar e ensinar línguas exige também que aprendamos a reconhecer e respeitar a legitimidade dos diversos povos que atuam e interagem por meio delas; povos marcados por uma heterogeneidade tamanha que seria impossível 
descrevê-los de modo simplista ou conhecê-los em suas particularidades. Portanto, tudo isso deve ser considerado no momento de planejar nossa abordagem em sala de aula.

O primeiro passo é definir minimamente o que pensamos sobre língua e linguagem ao prepararmos nosso curso. Minha atuação como professora de línguas (portuguesa e espanhola) está pautada na noção de língua como uma atividade social situada, assim como defende Marcuschi ao tratar de gêneros textuais:

\begin{abstract}
Partimos do pressuposto básico de que é impossível se comunicar verbalmente a não ser por algum gênero, assim como é impossível se comunicar verbalmente a não ser por algum texto. Em outros termos, partimos da idéia de que a comunicação verbal só é possível por algum gênero textual. Essa posição, defendida por Bakhtin [1997] e também por Bronckart (1999) é adotada pela maioria dos autores que tratam a língua em seus aspectos discursivos e enunciativos, e não em suas peculiaridades formais. Esta visão segue uma noção de língua como atividade social, histórica e cognitiva. Privilegia a natureza funcional e interativa e não o aspecto formal e estrutural da língua (MARCUSCHI, 2002, p. 21).
\end{abstract}

Por compreender esse caráter sociohistórico e sociointerativo da língua, utilizei durante as aulas variados gêneros discursivos como ferramentas de ensino de leitura em espanhol. Tendo em vista que a tarefa principal dos estudantes seria a de produção textual, antes era necessária essa etapa de recepção. Os textos selecionados eram, em sua maioria, multissemióticos, pois não se restringiam a uma única linguagem (cf. ROJO e MOURA, 2012). Como descreve Marcuschi a este respeito,

Esses gêneros que emergiram no último século no contexto das mais diversas mídias criam formas comunicativas próprias com um certo hibridismo que desafia as relações entre oralidade e escrita e inviabiliza de forma definitiva a velha visão dicotômica ainda presente em muitos manuais de ensino de língua. Esses gêneros também permitem observar a maior integração entre os vários tipos de semioses: signos verbais, sons, imagens e formas em movimento (MARCUSCHI, 2002, p. 20).

Cada uma dessas semioses ajuda a compor o texto em sua totalidade e nenhuma deve ser desprezada no processo de leitura, que deve estruturar-se em três momentos (cf. SOLÉ, 1998): o de pré-leitura, no qual se ativam os conhecimentos prévios dos alunos sobre o tema e criam-se hipóteses sobre o que será lido; o de leitura, quando efetivamente leem o texto, buscando compreendê-lo e construir sentidos; e o de pósleitura, fase em que se estimula a criticidade dos discentes quanto ao tema abordado. Isso garante um estudo do texto como um todo, por explorar sua temática e os significados que podem ser produzidos socialmente por seus leitores em distintas circunstâncias.

Em casos de gênero literário, é primordial observar e apontar também seu aspecto estético (cf. SANTOS, 2005), ou seja, seu estilo de linguagem, a escolha de vocabulário, estruturas sintáticas peculiares, frases de efeito etc. O fundamental é que se desconstrua a lógica tradicional e ultrapassada do trabalho com o texto apenas com a finalidade de exemplificar expressões linguísticas ou normas gramaticais, configurandose numa "atividade árida e tortuosa de decifração de palavras", como argumenta Kleiman (2002, p. 16). 
Outra importante contribuição para refletirmos sobre o assunto, ainda focado no contexto do ensino de línguas, é, entre outros, o seguinte fragmento dos Parâmetros Curriculares Nacionais de Língua Portuguesa:

Toda educação verdadeiramente comprometida com o exercício da cidadania precisa criar condições para o desenvolvimento da capacidade de uso eficaz da linguagem que satisfaça necessidades pessoais - que podem estar relacionadas às ações efetivas do cotidiano, à transmissão e busca de informação, ao exercício da reflexão. De modo geral, os textos são produzidos, lidos e ouvidos em razão de finalidades desse tipo. Sem negar a importância dos que respondem a exigências práticas da vida diária, são os textos que favorecem a reflexão crítica e imaginativa, o exercício de formas de pensamento mais elaboradas e abstratas, os mais vitais para a plena participação numa sociedade letrada (BRASIL, 1998, p. 25).

Essa argumentação é relevante para pensarmos no quanto a atividade de produção textual promovida pelo nosso projeto está conectada a um trabalho de letramento crítico, visto que favoreceu uma formação dos estudantes enquanto cidadãos críticos e reflexivos, que conseguiram ampliar sua forma de ação, interação e intervenção na sociedade através da leitura e da escrita (cf. BAPTISTA, 2010). Do mesmo modo, essa experiência gerou uma mudança na relação desses alunos com o mundo da literatura, imaginada pelo senso comum como algo inalcançável e do qual eles só seriam capazes de participar como leitores, e não como escritores. O que também propiciou uma transformação desse olhar foi o fato de termos como parceira uma editora cartonera, cujo propósito é tornar os livros mais acessíveis, possibilitando uma oportunidade de publicação por meios independentes, como uma alternativa às grandes editoras.

A análise dessa prática discursiva - a escrita - nos remete ainda à consideração de que os estudantes implicados no projeto atuaram tanto como leitores quanto como produtores de textos, constituindo-se como atores capazes de atividades linguísticas e práticas sociais mediadas pelos gêneros discursivos, estando atentos às especificidades das situações comunicativas (cf. ROJO, 2002). Em outras palavras, esses discentes atuaram como sujeitos que expressaram sua forma de enxergar seu entorno por meio de uma performance de linguagem escrita.

De maneira mais abrangente, há diversos documentos oficiais brasileiros que estabelecem e orientam o trabalho docente apoiando-se nos conceitos mencionados nesta seção. Uma ideia que resume o raciocínio que me moveu durante a criação do projeto do livro cartonero foi a de que

Numa escola inspirada na estética da sensibilidade, o espaço e o tempo são planejados para acolher e expressar a diversidade dos alunos e oportunizar trocas de significados. Nessa escola, a descontinuidade, a dispersão caótica, a padronização, o ruído, cederão lugar à continuidade, à diversidade expressiva, ao ordenamento e à permanente estimulação pelas palavras, imagens, sons, gestos e expressões de pessoas que buscam incansavelmente superar a fragmentação dos significados e o isolamento que ela provoca (BRASIL, 2000a, p. 63).

Portanto, nossas atividades estiveram em consonância com esse entendimento de como deve ser concebido e ocupado o ambiente educacional, um lugar onde os 
significados são construídos coletivamente ao respeitarmos a diversidade e heterogeneidade de pensamentos.

É nesse espaço, e para além dele, que devem ocorrer as interações entre todos aqueles que compõem essa comunidade escolar. A interdisciplinaridade é um meio eficaz e produtivo de viabilizar essas trocas, pois "supõe um eixo integrador, que pode ser o objeto de conhecimento, um projeto de investigação, um plano de intervenção" (BRASIL, 2000a, p. 76) e se origina "da necessidade sentida pelas escolas, professores e alunos de explicar, compreender, intervir, mudar, prever, algo que desafia uma disciplina isolada e atrai a atenção de mais de um olhar, talvez vários" (BRASIL, 2000a, p. 76). Embora não tenha envolvido diretamente professores de outras disciplinas, nosso projeto dialoga claramente com outras áreas do saber, e não exclusivamente com a de línguas estrangeiras.

Quanto à particularidade desse campo do conhecimento, me chamaram a atenção os objetivos das competências e habilidades atreladas ao ensino de linguagens, códigos e suas tecnologias, definidos pelos PCNs. Alguns deles são que o educando possa "compreender e usar os sistemas simbólicos das diferentes linguagens como meios de organização cognitiva da realidade pela constituição de significados, expressão, comunicação e informação" (BRASIL, 2000b, p. 10) e, se focarmos no ensinoaprendizagem de língua espanhola, "conhecer e usar língua(s) estrangeira(s) moderna(s) como instrumento de acesso a informações e a outras culturas e grupos sociais" (BRASIL, 2000b, p. 10).

Essas orientações são reforçadas em documentos posteriores, adequando-se às modificações que a educação experienciou no país e insistindo que o ensino de línguas estrangeiras deve contribuir para a construção da cidadania, priorizando um conjunto de valores, não de códigos definitivos e imutáveis (cf. BRASIL, 2006).

\section{Breve história das editoras cartoneras}

As editoras cartoneras estão presentes em diversas partes do mundo nos dias atuais e são fruto de uma ideia que se concretizou em 2003, em um contexto de crise financeira na Argentina, quando um grupo de trabalhadores que se encontravam desempregados se reuniram para elaborar soluções estratégicas contra os duros efeitos provenientes desse colapso econômico. Naquele período, uma imagem que se tornou rotineira no país foi a de milhares de catadores transportando suas cargas de papelão em vagões de trens antes desativados, agora destinados especificamente para isso.

Essa nova realidade foi o que tornou possível pôr em prática a engenhosidade e criatividade daqueles amigos que se uniram em uma cooperativa e criaram a Eloísa Cartonera, uma editora de livros cujas capas eram feitas de cartón ("papelão" em português), palavra da qual deriva o termo cartonera/o para se referir tanto à editora quanto às obras produzidas. Toda essa produção é feita manualmente, desde o trabalho de escolha do papelão a ser reciclado - comprado dos catadores - até a finalização dessa fatura que é o livro, passando pela definição das medidas para o corte das caixas selecionadas, pela produção da arte que estampará a capa e pela impressão dos textos que comporão a obra.

O que se pode notar a respeito desse processo é que estamos diante de uma editora como outra qualquer, salvo pela especificidade de que as capas são criadas a partir da reutilização do papelão, isto é, de um material antes provisório e que seria 
descartado, transformando-se em lixo. Além disso, cada capa recebe um tratamento particular, personalizado, bem diferente da imagem de uma produção em série na qual se perde a essência do significado de cada etapa. Com os livros cartoneros, o que chama a atenção é que não há ao menos duas capas idênticas; absolutamente todas são diferentes, ainda que se repitam as combinações de cores de fundo e título, já que não se trata de um trabalho mecânico ou realizado por máquinas, e sim pelas próprias mãos dos sujeitos envolvidos em sua confecção.

O êxito da Eloísa Cartonera, localizada em La Boca, Buenos Aires, fez com que essa nova forma - mais acessível, é importante destacar - de editar e publicar livros inspirasse pessoas de outros países, e o Brasil foi um deles. Desde que conheci a editora Ganesha Cartonera, criada em 2018, no Rio de Janeiro, por Ary Pimentel, professor da Faculdade de Letras da Universidade Federal do Rio de Janeiro, me interessei pela possibilidade de levar essa atividade para dentro do ambiente escolar, mas ainda não sabia como o faria. $\mathrm{O}$ intuito era integrar essa ideia inovadora à minha prática como docente de línguas, com foco na produção de textos. Até que tudo isso se materializasse no projeto final, levaríamos algum tempo, o que será esmiuçado a seguir.

\section{Circunstâncias de realização do projeto}

Houve uma ocasião em que, enquanto preparava materiais para mais uma aula de língua espanhola, deparei-me com uma sugestão de atividade em um livro didático. Trata-se da obra Confluencia, mais especificamente da "Unidad 2 - Ecopolémicas" do volume 3, apropriado para uso no último ano do Ensino Médio. Há uma proposta de projeto final para a referida unidade, por meio do qual os autores apresentam um pouco do universo cartonero, contando a história da editora pioneira, a Eloísa Cartonera, e oferecendo fotografias de diversos livros cartoneros produzidos na Argentina e no México.

Foi a partir da leitura das indicações presentes no material mencionado que as ideias começaram a se organizar e pude definir e planejar o trabalho que desenvolveríamos nos próximos meses, adequando-o ao contexto em que estávamos, estudantes e eu, inseridos.

O projeto foi realizado durante o primeiro semestre de 2019, tornando-se parte integrante do que eu havia programado para a disciplina Língua Estrangeira IV Espanhol com a turma do quarto ano do Ensino Médio integrado ao Técnico em Telecomunicações, do CEFET/RJ, no campus Petrópolis. ${ }^{1}$ Quanto aos sujeitos implicados, além do docente responsável e dos alunos dessa turma, foi fundamental o auxílio do professor Ary Pimentel, que, como já informado, é também o criador da Ganesha Cartonera, e cujo apoio foi imprescindível para que conseguíssemos publicar os textos e para que aprendêssemos a manusear e construir coletivamente as capas.

\section{Detalhes e etapas do projeto}

Tão logo tive a oportunidade, ainda no início do semestre, apresentei à turma o projeto que havia idealizado: cada um dos estudantes produziria um texto em língua espanhola, sobre tema a ser definido, e essas produções seriam reunidas e publicadas em

\footnotetext{
${ }^{1} \mathrm{Na}$ ocasião da realização do projeto, a instituição ainda ofertava um curso de ensino médio de quatro anos naquele campus.
} 
um livro cartonero. Além disso, informei que o ideal seria desenvolvê-lo ao longo daquele período e que decidiríamos em conjunto uma série de definições, tais como temáticas abordadas, gêneros literários, tamanho dos textos, título do livro, entre outros. O mais importante para que pudéssemos dar o passo seguinte era a recepção dos alunos a essa ideia. Uma vez que eles concordaram, se animaram e se comprometeram a levá-la adiante, desenvolvemos, a cada encontro, um pouco de cada etapa, sempre respeitando o planejamento previsto e adequado para o ensino de língua espanhola para uma turma do quarto ano.

Cabe ressaltar que a motivação para a escolha desse grupo foi o fato de que os estudantes, por estarem no último ano escolar, teriam mais subsídios para produzir textos de gêneros discursivos dissertativos, mais extensos, com ideias mais complexas, e cujos temas já tivessem sido discutidos em sala nas aulas da disciplina, em que seriam fornecidos textos escritos, imagens, áudios e vídeos sobre cada um. Da mesma forma, a própria produção de um livro do tipo cartonero suscita debates sobre assuntos diversos, como meio ambiente e sustentabilidade, crise financeira, mercado de trabalho, entre outros, ainda não apropriados para uma turma que estaria em seus primeiros contatos com a língua espanhola.

Para fins de padronização, e levando em consideração que os discentes implicados já haviam estudado vários gêneros literários, tanto em Língua Espanhola quanto nas disciplinas de Língua Portuguesa, Língua Inglesa e Produção de Textos, a sugestão inicial foi a do gênero crônica, tendo em vista que o estudaríamos naquele período. Contudo, a cada encontro alguns estudantes manifestaram discordância e sinalizaram o gênero em que se sentiriam mais à vontade para a escrita. Portanto, a decisão final foi a de que, a critério de cada um, os gêneros contemplados seriam: crônica, poesia e conto, mas todos sobre um mesmo tema, o meio ambiente.

Ainda quanto à forma dos textos, cada um deveria ter até quatro páginas, já que o grupo totalizava vinte e um alunos e, dependendo do formato final da capa, correríamos o risco de o material impresso não caber confortavelmente nela. Para que possamos visualizar, o padrão de medidas de cada página do miolo de um livro cartonero, o mesmo definido para o nosso caso, é o de aproximadamente $15 \mathrm{~cm}$ (largura) x $21 \mathrm{~cm}$ (altura), o equivalente à metade de uma folha do tipo A4. Já as medidas da capa (aberta) são $34 \mathrm{~cm}$ (largura) x $23 \mathrm{~cm}$ (altura). ${ }^{2}$

Tendo-se todas essas definições, seguiu-se à efetivação do projeto, em diferentes etapas. Os primeiros passos foram as conversas em sala sobre assuntos e conteúdos que eu havia preparado. O tema que seria recorrente, e que melhor se adequou ao nosso objetivo final - a produção de um livro cartonero -, foram as preocupações com o meio ambiente e discussões associadas a esta área mais abrangente. Para motivarem nossas conversas e fornecerem tópicos que serviriam de inspiração para os alunos, levei às aulas textos de diferentes gêneros discursivos, sendo a maioria multimodais, para uma abordagem mais completa e um tratamento dos temas de modo mais heterogêneo. Alguns exemplos dos materiais que estudamos são os seguintes:

1. Uma imagem que retratava um grupo de mulheres extraindo o estigma da flor de açafrão, para falarmos sobre a superexploração da natureza para fins lucrativos. Esta foi a mesma fotografia utilizada na abertura da Unidad 2 do livro didático Confluencia;

\footnotetext{
${ }^{2}$ As medidas com que trabalhamos no nosso projeto não são definitivas nem as únicas viáveis, isto é, cada editora pode alterá-las e estabelecer novos padrões conforme desejarem.
} 
2. Fragmentos do poema "Oficina y denuncia", extraído de Poeta en Nueva York, de Federico García Lorca, provocando uma reflexão sobre maneiras de denunciar nossa indignação diante de certos fatos, como a crueldade contra milhões de animais que são mortos anualmente para satisfazer à indústria alimentícia, segundo escreveu Lorca. Essa atividade foi uma adaptação de outra proposta de exercício da supracitada Unidad 2 ;

3. A fábula "La Fábula de la Tortuga Marina y la Medusa de Plástico", de Sarah Nelms e Kate Nelms, que, como o título adianta, chama a atenção para os já conhecidos casos de animais marinhos afetados pelos dejetos lançados ao mar;

4. A canção “¿Dónde jugarán los niños?”, do grupo musical Maná, a fim de ampliarmos nosso vocabulário sobre aquilo que já vínhamos comentando: desastres naturais, cuidados com o meio ambiente e consequências dos atos de hoje para as gerações vindouras. Estudamos a letra, ouvimos a música e, por último, vimos o videoclipe oficial da banda;

5. A crônica "Una mañana de mayo pasado", de Juan Gossaín, para tratarmos da contaminação da água do mar, em especial pelo derramamento de petróleo;

6. A reportagem "Vidas precarias, el paro juvenil en España", da revista digital Habla Cultura, que suscita o debate sobre crise e precariedade laboral e, ainda que trate do contexto espanhol, nos permite fazer uma ponte com o caso da crise financeira que atingiu inúmeros trabalhadores na Argentina no início dos anos 2000, a partir da qual surge a cooperativa que cria a Eloísa Cartonera, em 2003.

Vale a pena reforçar que a escolha, pelos discentes, do tema específico que abordariam em seu conto, sua crônica ou sua poesia não foi, de maneira alguma, imposta. Então, assim como decidiram o gênero literário com que tinham mais afinidade, partiu deles a opção de focar sua escrita no esgotamento dos recursos naturais, nas formas alternativas de alimentação, na poluição, nos meios impróprios de descarte do lixo, no desmatamento, nas enchentes, na reciclagem ou em tantos outros possíveis. $\mathrm{O}$ assunto geral, o meio ambiente, ao qual estão atreladas essas discussões, foi apresentado como sugestão e aceito pela turma. Com o tema definido, eles já poderiam começar a escrever.

De acordo com o que afirmei ao início do artigo, a atividade de produção textual por parte dos estudantes compreendeu distintas etapas, necessárias para o ensinoaprendizagem dessa destreza no contexto de um curso de espanhol como língua estrangeira da educação básica. Como os textos foram escritos fora do horário de nossas aulas, não acompanhei diretamente um dos passos desse processo: o rascunho. Esta é naturalmente a primeira tarefa com que o autor de um texto se depara ao produzi-lo, uma vez que há uma versão inicial, que surge a partir das ideias projetadas em um primeiro momento, e as versões subsequentes, resultado de rearranjos feitos por esse sujeito que escreve, durante a etapa de escrita propriamente dita, ou após a leitura de suas anotações anteriores.

Sendo assim, minhas contribuições aos estudantes começaram a partir do momento em que recebi seus escritos. Ao revisá-los, após fazer mais de uma leitura de cada um, inseri os comentários necessários para que pudesse devolvê-los o quanto antes, a fim de que eles tivessem tempo hábil para relê-los e reescrevê-los dentro do prazo que havíamos estipulado. Já que era minha primeira experiência com esse tipo de projeto, que envolveu a escrita de textos literários, com estéticas próprias, e que exigia dos alunos mais autonomia, criatividade e liberdade de produção, tive o cuidado de não interferir na 
decisão temática, nos modos como os textos estavam dispostos, nem nos sentidos que cada um quis construir, fazendo recomendações somente com relação à correção linguística, à coesão, à coerência e à adequação. Além disso, não apenas lhes devolvi os textos, mas também proporcionei um feedback individualizado.

Houve ainda uma última revisão, após receber a versão final entregue por eles, para confirmação de que estavam prontos para serem enviados à editora. Antes disso, os alunos elegeram, por meio de votação, o título da obra, entre três que eles mesmos haviam proposto: Los susurros del medio ambiente.

Quanto à parte escrita do livro, tudo já estava estabelecido: temáticas, gêneros, tamanho, prazos (para entregas parciais e final do texto) e título. Faltava-nos aprender a reciclar as caixas de papelão, dando-lhes um novo destino. Para isso, o professor Ary Pimentel ofereceu uma oficina de produção de capas cartoneras, que teve duração de quatro horas e foi realizada no dia 27 de junho de 2019 na própria instituição. Na oficina, o criador da editora Ganesha Cartonera ensinou cada um dos procedimentos necessários e a ordem em que devem ser executados, como descrito a seguir: 1) selecionar o papelão, tendo em vista sua qualidade (o ideal é que seja mais firme) e suas dimensões. É preciso que seja um pouco maior que o tamanho final desejado, para que, caso haja equívoco na hora do recorte, seja possível remediar e evitar o desperdício; 2) marcar as medidas no papelão, com uma régua ou, de preferência, com um molde, a fim de facilitar o trabalho; 3) recortá-lo cuidadosamente com um estilete, respeitando as marcações e utilizando uma régua de ferro para auxiliar esta etapa; 4) decidir qual dos lados constituirá a parte interna da capa e qual será a externa e, em seguida, dobrar o papelão, lembrando-se de deixar o espaço que será ocupado futuramente pelo miolo; 5) uma vez dobrado, o passo subsequente é escolher as cores de fundo das capas, pintá-las e deixar a tinta secar. Vale destacar que cada uma poderá ter um fundo diferente; 6) com as capas secas, parte-se para a última tarefa, a de inserir o título do livro. Para fazê-lo, usamos um estêncil (molde vazado) - criado por Ary exclusivamente para nossa obra - com as palavras e as imagens que aplicaríamos com um aerossol. Mais uma vez, o esquema de cores fica a critério de cada pessoa.

A oficina teve duração de quatro horas, pois, após as explicações e demonstrações, os estudantes produziram várias capas naquela mesma ocasião, executando todos os passos recentemente aprendidos.

Apesar de termos conseguido preparar muitas capas, ainda não eram $o$ suficiente para abrigar os cem exemplares previstos. Portanto, agendamos outro encontro exclusivamente para confeccionar uma quantidade maior, desta vez sem o professor Ary. A atividade foi realizada fora do horário de aula, mas dentro da instituição, aproveitando o período de provas de segunda chamada - que poucos deles teriam que fazer - para não interferir no planejamento de nossas aulas, nem no de outros docentes. A respeito de todo esse processo, cabe assinalar que não houve custos para os estudantes, desde a seleção do papelão até a aquisição das ferramentas usadas.

Entramos em recesso e, neste período, recebi as versões finais de alguns textos, que, como afirmei anteriormente, voltei a revisar para que pudessem ser encaminhados à editora, formatados e enviados à gráfica. Reunimos a turma mais uma vez em torno do nosso livro já no dia de seu lançamento, que ocorreu durante a Semana de Ensino, Pesquisa e Extensão (SEPEX) de 2019 do CEFET/RJ. Além do lançamento, os livros ficaram expostos durante todo o evento, cujo tema foi "Bioeconomia: diversidade e riqueza para o desenvolvimento sustentável", ao qual nosso projeto estava totalmente 
alinhado. ${ }^{3}$ Devido a complicações que aconteceram na gráfica responsável, não concluímos a impressão das cem cópias antes da SEPEX 2019. Por essa razão, a solução que encontramos para podermos lançar os livros e deixá-los em exposição foi usar um exemplar impresso a partir da última versão disponibilizada pela editora (em arquivo digital), além de exibir todas as capas que havíamos produzido.

Alguns meses mais tarde, o livro foi finalmente impresso em cem exemplares e publicado (com ISBN) pela Ganesha Cartonera em parceria com a Desalinho, tornandose a primeira publicação em livro dos estudantes envolvidos no projeto. Tratou-se de um processo meticuloso, longo e trabalhoso, mas, acima de tudo, gratificante. Foi uma forma de perceber e mostrar que teoria e prática caminham entrelaçadas e que as atividades de produção textual no ensino de língua estrangeira podem transcender o espaço da sala de aula e superar exercícios de escrita baseados apenas no preenchimento de lacunas ou na reprodução de modelos restritos de enunciados. Foi apenas uma entre todas as estratégias que a mente humana é capaz de criar quando o desejo maior é o de proporcionar uma educação inovadora e transformadora.

\section{Considerações Finais}

Neste artigo, busquei compartilhar uma experiência que tinha como foco inicial a produção de texto em língua espanhola pelos alunos do quarto ano do curso técnico em Telecomunicações integrado ao Ensino Médio do CEFET/RJ, na unidade de Petrópolis. Entretanto, o projeto ganhou outras proporções - esperadas, mas que ainda não eram garantidas - e superou minhas expectativas, chegando à produção e publicação de um livro cartonero. O que tornou tudo possível foi um conjunto de fatores e atores: o fato de estarmos em uma instituição federal de educação, ciência e tecnologia, onde há estímulos à produção e intercâmbio de saberes, além de uma infraestrutura que nos permitiu realizar tudo o que havíamos programado dentro do próprio instituto, ficando muito mais confortável para os estudantes; estes, por sua vez, se comprometeram com o projeto, se dedicaram e venceram seus medos quanto às dificuldades de escrita, apesar de uns poucos terem desistido de enviar seus textos, mesmo estando presentes em todas as demais etapas; outra pessoa cujo apoio foi primordial é o criador da Ganesha Cartonera, onde o livro foi publicado. O professor Ary Pimentel nos possibilitou a ponte com a editora e foi quem ofereceu a oficina de confecção de capa de papelão; outros atores que tampouco podem ser esquecidos são aqueles professores de outras disciplinas que, ainda que indiretamente, nos acompanharam e se mostraram dispostos a contribuírem no que fosse necessário.

Ao final do processo, pode-se avaliar o projeto como uma forma de ação que pode alicerçar um ensino de língua estrangeira preocupado com a formação global do aluno, como aconselham os principais documentos norteadores da educação básica brasileira. Não se trata de um modelo, mas sim uma opção (entre tantas) de intervenção no espaço escolar. Em termos mais pessoais, toda essa jornada foi muito significativa tanto para mim quanto para os discentes e a editora de livros cartoneros, uma vez que todos tivemos uma primeira experiência: eu, como professora propondo esse tipo de

\footnotetext{
${ }^{3}$ A SEPEX, sempre celebrada no mês de outubro, é um evento que faz parte da Semana Nacional de Ciência e Tecnologia, portanto seu tema é o mesmo escolhido pelo Ministério da Ciência, Tecnologia, Inovações e Comunicações (MCTIC), órgão que a promove.
} 
projeto; os estudantes, escrevendo uma crônica, conto ou poesia em espanhol e publicando em uma coletânea; e a Ganesha Cartonera, editando um livro em língua estrangeira com textos de alunos de ensino médio.

Apesar de a análise geral ser positiva, é preciso refletir sobre as complicações que enfrentamos, que foram mínimas, mas não desprezíveis, por isso é desejável evitar que se repitam. Talvez o que mais nos preocupou tenha sido o incidente com a gráfica, que fez com que os livros não fossem impressos a tempo do lançamento, agendado com antecedência para acontecer durante a SEPEX 2019 do CEFET/RJ. Em outra oportunidade, o ideal seria desenvolver o projeto em mais tempo, ao longo de um ano letivo, no mínimo, para que haja um intervalo maior entre as etapas, podendo-se fazer ajustes em caso de imprevistos. Minha programação foi para um semestre porque eu não poderia estar com eles nos meses seguintes, uma vez que estava na condição de Professora Substituta e meu contrato se encerraria em julho daquele ano.

Considero, enfim, que o trabalho que desenvolvemos é bastante profícuo para a prática da interdisciplinaridade no ambiente escolar, atendendo a diferentes propósitos. $\mathrm{O}$ ideal é envolver o máximo de docentes da instituição, segundo os diálogos que um projeto desse tipo possa provocar. Isso demandará ainda mais tempo de planejamento e organização, mas garantirá aos discentes e docentes uma experiência mais completa, abrangente e integrada.

\section{Referências}

BAKHTIN, M. Estética da criação verbal. São Paulo: Martins Fontes, 2003.

BAPTISTA, L. M. T. R. Traçando caminhos: letramento, letramento crítico e ensino de espanhol. In: BARROS, C. S.; COSTA, E. G. M. (coord). Espanhol: ensino médio. (Coleção Explorando o Ensino; v. 16). Brasília: Ministério da Educação, Secretaria de Educação Básica, 2010. p. 119-136.

BRASIL. Orientações curriculares para o ensino médio. Linguagens, códigos e suas tecnologias. Brasília: Ministério da Educação, Secretaria de Educação Básica, 2006.

BRASIL. Parâmetros curriculares nacionais - Ensino Médio. Parte I - Bases Legais. Ministério da Educação. Secretaria de Educação Média e Tecnológica. Brasília: Ministério da Educação, 2000a.

BRASIL. Parâmetros curriculares nacionais - Ensino Médio. Parte II - Linguagens, Códigos e suas Tecnologias. Ministério da Educação. Secretaria de Educação Média e Tecnológica. Brasília: Ministério da Educação, 2000b.

BRASIL. Parâmetros curriculares nacionais - Língua Portuguesa. Ministério da Educação e do Desporto. Secretaria de Educação Fundamental. Brasília: Ministério da Educação, 1998.

KLEIMAN. A. Oficina de Leitura: Teoria e Prática. 9. ed. Campinas: Pontes, 2002. 
MARCUSCHI, L. A. Gêneros textuais: definição e funcionalidade. In: DIONISIO, A. P.; MACHADO, A. R.; BEZERRA, M. A. (orgs.). Gêneros Textuais \& Ensino. Rio de Janeiro: Lucerna, 2002. p. 19-34.

PINHEIRO-CORREA, P. et al. Confluencia 3 - manual do professor. São Paulo: Moderna, 2016.

ROJO, R. H. R. Concepção de leitor e produtor de textos nos PCNs: "Ler é melhor do que estudar". In: FREITAS, M. T. A.; COSTA, S. R. (orgs.). Leitura e Escrita na Formação de Professores. São Paulo: Editora Musa, 2002. p. 31-52.

ROJO, R. H. R.; MOURA, E. (orgs.). Multiletramentos na escola. São Paulo: Parábola Editorial, 2012.

SANTOS, A. C. El género literario y la comprensión lectora en clases de E/LE. Actas del II Simposio internacional de didáctica de español para extranjeros, Rio de Janeiro, v. 1, p. 457-463, 2005.

SOLÉ, I. Estrategias de lectura. 8. ed. Barcelona: Graó, 1998.

Recebido em 31 de maio de 2020

Aceito em 20 de junho de 2020 